\title{
Prestressing Concrete with CFRP Composites for Sustainability and Corrosion-Free Applications
}

\author{
A. Belarbi ${ }^{1}$, M. Reda ${ }^{1}$, P. Poudel ${ }^{1}$, H. Tahsiri ${ }^{1}$, M. Dawood ${ }^{1}$, and B. Gencturk ${ }^{2}$ \\ ${ }^{1}$ University of Houston, Civil and Environmental Engineering, Houston, TX, USA \\ ${ }^{2}$ University of Southern California, Civil and Environmental Engineering, Los Angeles, CA, USA
}

\begin{abstract}
Advancement in material science has enabled the engineers to enhance the strength and long-term behavior of concrete structures. The conventional approach is to use steel for prestressed bridge girders. Despite having good ductility and strength, beams prestressed with steel are susceptible to corrosion when subjected to environmental exposure. The corrosion of the prestressing steel reduces load carrying capacity of the prestressed member and result in catastrophic failures. In the last decades, more durable composite materials such as Aramid Fiber Reinforced Polymer (AFRP), Glass Fiber Reinforced Polymer (GFRP) and Carbon Fiber Reinforced Polymer (CFRP) have been implemented in concrete structures as a solution to this problem. Among these materials, CFRP stands out as a primary prestressing reinforcement, which has the potential to replace steel and provide corrosion free prestressed bridge girders. Despite its promise, prestressing CFRP has not frequently been used for bridge construction worldwide. The major contributing factor to the lack of advancement of this promising technology in the United States (U.S.) is the lack of comprehensive design specifications. Apart from a limited number of guides, manuals, and commentaries, there is currently no standard or comprehensive design guideline available to bridge engineers in the U.S. for the design of concrete structures prestressed with CFRP systems. The main goal is to develop design guidelines in AASHTO-LRFD format for concrete bridge girders with prestressing CFRP materials. The guidelines are intended to address the limitation in current AASHTO-LRFD Bridge Design Specifications which is applicable for prestressed bridge girders with steel strands. To accomplish this goal, some of the critical parameters that affect the design and long-term behavior of prestressed concrete bridge girders with prestressing CFRP systems are identified and included in the research work. This paper presents preliminary results of an experimental study that is part of a National Highway Co-operative Highway Research Program (NCHRP) project.
\end{abstract}

\section{Introduction}

Prestressed reinforced concrete for highway bridges has been in progress since 1951 [1]. At present, around $27 \%$ of all the highway bridges in the United States consist of prestressed concrete. Nearly all the prestressed beams use prestressing steel. The problem with steel prestressing reinforcement is corrosion (Figure 1). Prestressed steel beams have prestressing steel tendons under high stress with the relatively small cross-sectional area. The possibility of brittle fracture due to stress corrosion or hydrogen embrittlement is higher in higher strength steel. This may lead to the sudden failure of a bridge without any warning [3-4]. These have initiated the use of nonmetallic tendons such as Glass Fiber Reinforced Polymer (GFRP), Aramid Fiber Reinforced Polymer (AFRP) and Carbon Fiber Reinforced Polymer (CFRP) collectively referred to as Fiber Reinforced Polymers (FRPs). Among these materials, CFRP stands out as a primary prestressing reinforcement. The initial cost of CFRP is higher than that of GFRP and AFRP. Furthermore, all three FRPs are comparable regarding their tensile strength. The one thing that stands out the most for the CFRP is its high tensile stiffness. The durability properties of the CFRP are also excellent in comparison to other FRPs [5].

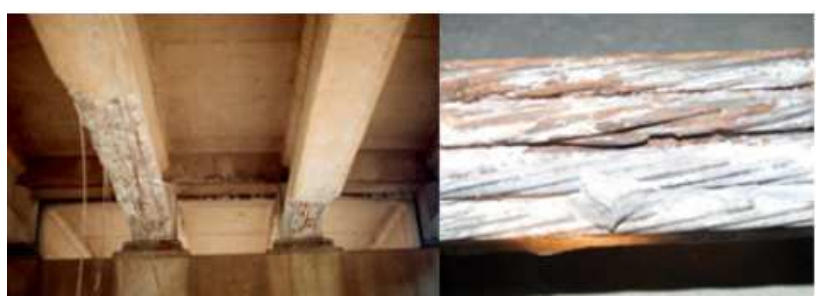

Fig. 1. Corrosion of the prestressing steel [2]

CFRPs are becoming a recognized alternative to traditional construction materials with a wide range of applications in current civil engineering practice. A novel example of these applications is the use of CFRP strands 
as prestressing reinforcement for prestressed concrete bridge girders, especially in aggressive environments where steel strands are susceptible to corrosion. CFRP materials have specific advantages such as high strengthto-weight and stiffness-to-weight ratios, and resistance to electrochemical corrosion. Despite their promise, however, prestressing CFRP strands have not frequently been used for bridge construction in the United States (US). The major contributing factor to the lack of advancement of this technology in the US is the lack of comprehensive design specifications.

\section{Previous Studies}

Many researchers have proven that CFRP can be an alternative to steel strands in prestressed concrete bridge applications, especially in aggressive environments where corrosion resistance is essential.

The flexural behavior of CFRP-prestressed beams with bonded tendons has been extensively studied in the past. Test results consistently indicate that while the behavior of CFRP-prestressed and steel-prestressed concrete beams are similar in many regards, there are several important differences which must be considered. These differences are primarily due to the linear-elastic nature of CFRP reinforcement. On the other hand, the flexural behavior of post-tensioned beams with unbonded CFRP tendons has been less studied comparing to the bonded prestressed beams with CFRP tendons. The failure of unbonded post-tensioned beams is generally attributed to concrete crushing. The fact that the cables are unbonded leads to release of stresses at critical sections and average it out along the tendon's length, so the load in the tendon will be less than their bonded counterpart. Therefore, the ultimate strength of the bonded specimens is higher than the unbonded specimens regardless of the tendon type.

Beams that are prestressed with CFRP can exhibit failure due to rupture of the tendons before crushing of the concrete, whereas the flexural design of prestressed steel beams is always defined by crushing of the concrete regardless of the reinforcement ratio.

The initial behavior of the beams prestressed with prestressing CFRP or steel is comparable. All beams exhibit a linear response before cracking. The tendon type had little impact on the uncracked stiffnesses and the cracking load, as the beam geometry, total prestressing force, and eccentricity of the prestressing force are comparable. After cracking, the beams prestressed with CFRP exhibited slightly lower stiffnesses than their steelprestressed counterparts. This is due to the slightly lower modulus of elasticity of the CFRP tendons as compared to steel tendons. Abdelrahman et al. tested four beams with two different types of prestressing CFRP under monotonic and fatigue loading. These four beams had the same span-to-depth ratio and 1:3.3 scale as the girders of first smart highway bridge built in Calgary, Alberta, Canada. They reported that the beams pre-tensioned with prestressing CFRP exhibit a significant deformation before failure. The beams tested under fatigue loading with a load range of $70 \%$ of cracking to cracking load survived 2 million cycles with little effect on beam stiffness. The capacity of the beams after fatigue loading was comparable to the capacity of the beams under monotonic loading. The length of the tested beams was $13.5 \mathrm{~m}$. [6]

Dolan et al. tested one beam pretensioned with harped prestressing CFRP and one beam pretensioned with harped prestressing steel under fatigue loading. The load range of the fatigue was approximately between $11 \%$ and $35 \%$ of the ultimate monotonic load which induces a stress range of $0.05 \sqrt{ } \mathrm{f}_{\mathrm{c}}$ and $0.6 \sqrt{ } \mathrm{f}^{\prime}{ }_{\mathrm{c}}$ on the bottom concrete fiber, respectively. The tendon stress varied from $0.28 \mathrm{f}_{\mathrm{pu}}$ to $0.36 \mathrm{f}_{\mathrm{pu}}$ for prestressing CFRP. They found that the fatigue behavior of the beam pretensioned with steel and prestressing CFRP is similar. Both beams were found to experience similar amounts of permanent deflection, the same crack distribution and the same strength due to fatigue load. They also found that the beam pre-tensioned with prestressing CFRP experienced no reduction in the capacity due to the fatigue loading. They also pointed out that special consideration must be given to the CFRP prestressed beams to avoid brittle failure, especially when the prestressing CFRP are harped. [7]

Heo et al. tested seven simply supported posttensioned beams with internally unbonded CFRP tendons (four rectangular and three T-beams). The test parameters were the prestressing reinforcement ratio, the initial prestressing, the loading type (three-point or four-point loading) and the section shape. Unstressed auxiliary bonded reinforcements (steel for the T-beams and CFRP for rectangular beams) were added to the bottom of the beam. Regardless of the reinforcement ratio, all the beams failed in flexure due to concrete crushing without tensile rupture of the unbonded prestressed tendons. Also, all rectangular beams maintained residual strength after the peak load, which is equal to section capacity of the beams after removing the top concrete cover. In addition, the type of loading affected the failure mode of the Tbeams as the beam tested in four-point loading failed in an explosive manner that took out the constant moment region without any residual capacity, however, the beam tested under 3-point loading showed a residual capacity after the peak. Moreover, the prestressing ratio affects the brittleness of the compression failure mode, as the higher the prestressing ratio, the higher the brittle compression failure will happen. Comparing the ductility of beams with auxiliary bonded steel bars with bonded CFRP tendons for rectangular sections, the ductility of the beams with auxiliary bonded steel bars were higher. Moreover, they evaluated the ductility of post-tensioned beams with CFRP tendons based on the absorbed elastic and inelastic energy under the load-deflection curve. The results showed that the calculated ductility overestimates the measured ones and need further refinement. [8]

Braimah et al. tested five unbonded post-tensioned concrete beams with two different prestressing reinforcement types (prestressing CFRP and steel) under fatigue flexural loading. The steel post-tensioned beams had bonded non-prestressed steel reinforcement, while the CFRP post-tensioned beams had bonded nonprestressed GFRP rods. A severe test regime was chosen that induced a stress range of about $100 \mathrm{MPa}$ in the 
bottom prestressing reinforcement. The beams were initially loaded past the cracking load and then unloading to obtain an initial load-deflection response. The fatigue tests were performed under four-point loading with a frequency of $1 \mathrm{~Hz}$. None of the post-tensioned beams survived the 2.0 million cycles. The failure of the posttensioned steel beams started by fracture of the nonstressed steel then the seven-wire prestressed strands. However, the failure of CFRP post-tensioned beams was initiated by the failure of the prestressed CFRP tendons, and non-prestressed GFRP rods didn't fail during the fatigue cycles. The fracture of the CFRP tendons occurred at the anchor's location. [9]

Kakizawa et al. investigated the behavior of beams fully and partially prestressed with CFRP. The prestress force and bonding properties were the test parameters. The results showed that the failure mode and deformation depend on the reinforcement system. In addition, the absorbed energy is affected by the reinforcing system, but little by the failure mode. The partially prestressed beams tended to have greater energy absorption than the fully prestressed beams. The fully prestressed beams showed no energy absorption after the failure of the FRP cable. However, the fully unbonded beams that failed by concrete crushing showed the same energy absorption after reaching the maximum load. [10]

Grace et al. investigated the behavior of multi-span CFRP prestressed continuous concrete bridges with external longitudinal post-tensioning using draped tendons and bonded transverse post-tensioning. The ductility of such a bridge system increased and mid-span deformation decreased compared to the behavior of a simply supported beam constructed with similar member properties. At the ultimate load stage, the progressive failure of CFRP tendons was observed. [11]

\section{Objectives}

The objectives of the current study are to; (1) study the behavior of prestressed beams with different prestressing CFRP systems under monotonic and fatigue loadings, (2) compare the behavior of beams post-tensioned and pretensioned with prestressing CFRP.

\section{Experimental Program}

\subsection{Beam Design}

Four full-scale prestressed beams were constructed at a precast plant. The beams are $711 \mathrm{~mm}$ deep AASHTO Type 'I' with a $203 \mathrm{~mm}$ cast-in-place composite deck. The span of the beams is $12 \mathrm{~m}$. All of the beams were reinforced in shear with steel stirrups to ensure a flexural dominant failure.

The post-tensioned beams "CPouDF" and "CPoDM" were stressed with five straight $19.3 \mathrm{~mm}$. twisted-wire prestressing CFRP cables. The cables inside the duct of the post-tensioned beam "CPoDM" were grouted with high strength cementitious grout. However, the cable on the other post-tensioned beam "CPouDF" left un-grouted (unbonded). The two pre-tensioned beams, "CPrSM" and "BPrSM", were stressed with eight straight $15.2 \mathrm{~mm}$. twisted-wire CFRP cables and twelve straight $12.7 \mathrm{~mm}$ round CFRP bars, respectively. Figure 2 shows the beam's dimensions, shear reinforcement distribution details, deck steel reinforcement details, and prestressing elements' locations. The CFRP cables and bars were stressed to the $60 \%$ of the guaranteed breaking load, provided by the manufacturer. The properties of the CFRP, based on conducted laboratory tests, are presented in Table 1.

Table 1. Prestressing CFRP properties

\begin{tabular}{|c|c|c|c|c|}
\hline $\begin{array}{c}\text { Beam } \\
\text { ID }\end{array}$ & $\begin{array}{c}\text { Diameter } \\
\text { (in.) }\end{array}$ & $\begin{array}{c}\text { Breaking } \\
\text { Load } \\
(\mathrm{kN})\end{array}$ & $\begin{array}{c}\text { Young's } \\
\text { Modulus } \\
(\mathrm{GPa})\end{array}$ & $\begin{array}{c}\text { Ultimate } \\
\text { Strain } \\
(\%)\end{array}$ \\
\hline Cable & 15.2 & 327.8 & 155 & 2.0 \\
\hline Cable & 19.3 & 467.9 & 153 & 1.7 \\
\hline Bar & 12.7 & 226.5 & 144 & 1.3 \\
\hline
\end{tabular}

\subsection{Fabrication}

All the beams were fabricated at the precast plant. The production of the beams was conducted in different batches. The girders were poured and stressed, and then a composite deck was added on the top.

The pre-tensioning is applied through the steel strands and transferred to the prestressing CFRP with couplers, as shown in Figure $3 \mathrm{a}-\mathrm{b}$. On the other hand, the posttensioning of the prestressing CFRP cables was done in sequence using a single hydraulic jack, as shown in Figure 3c.

For bonded post-tensioned beam, a high strength cementitious non-shrinkable grout was used for grouting the prestressing CFRP. The grouting was performed at the precast plant, immediately after the post-tensioning process.

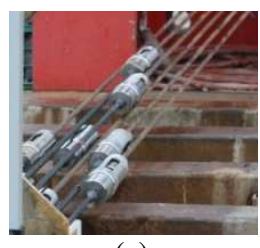

(a)

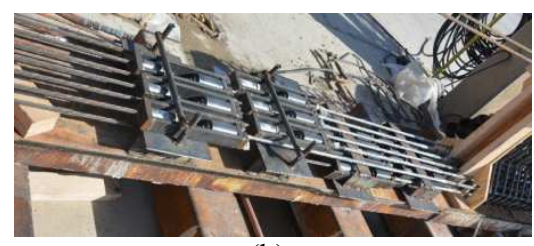

(b)

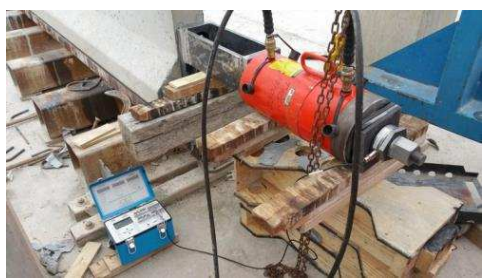

(c)
Fig. 3. Pre-tensioning and post-tensioning of prestressing CFRP cables and bar 


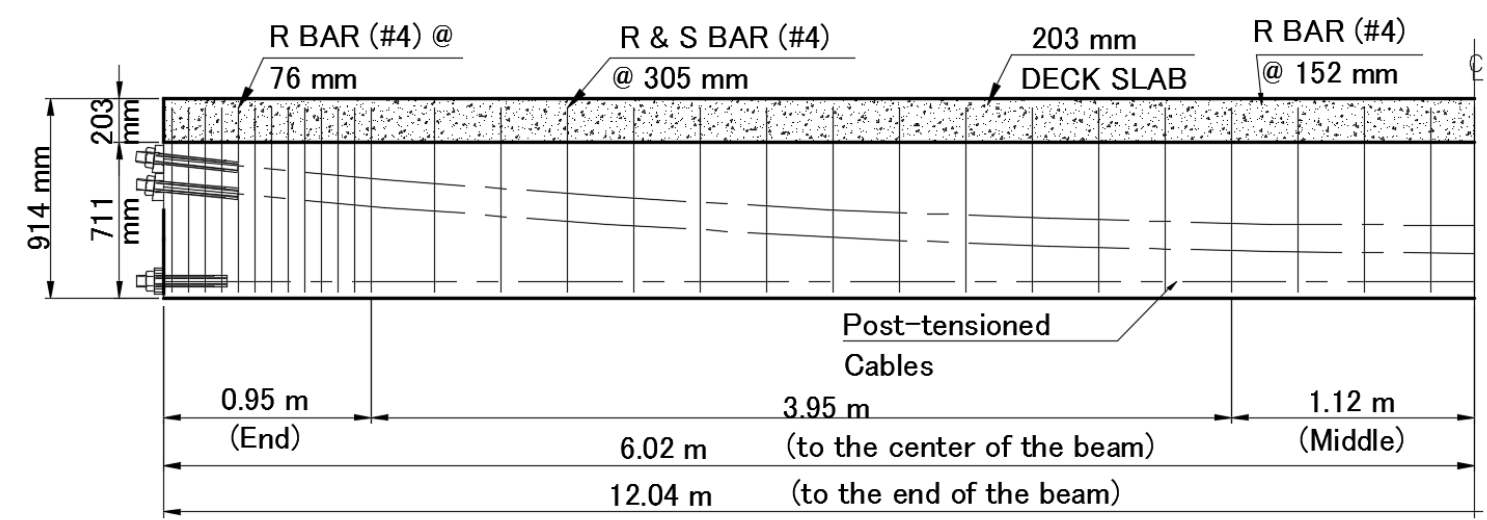

(a)

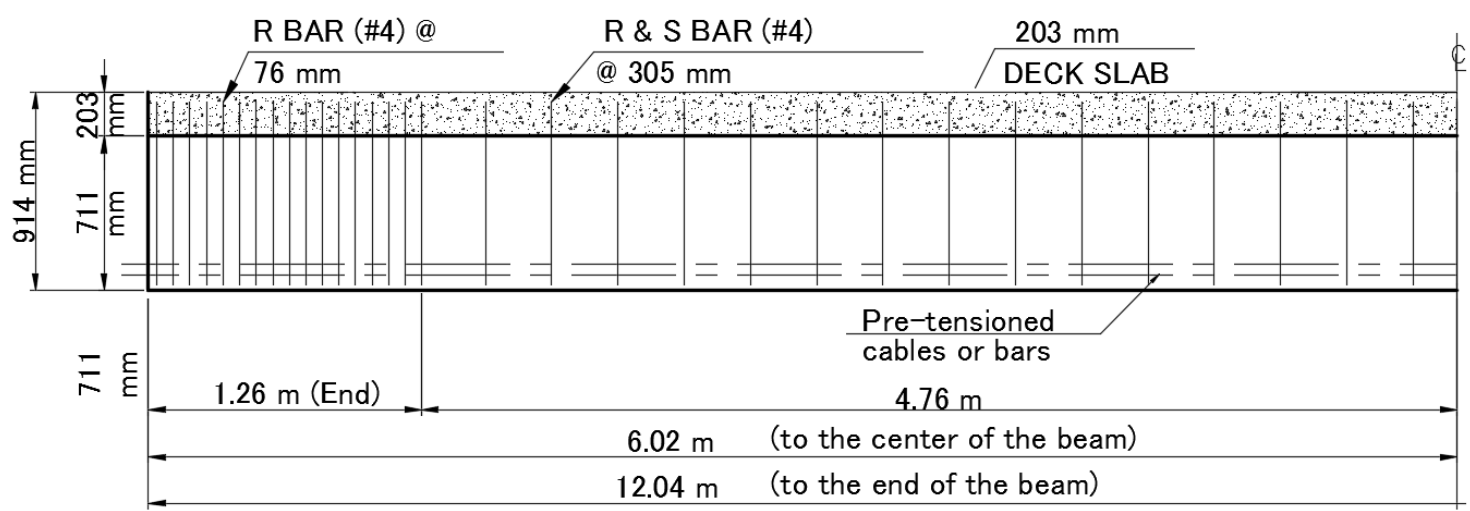

(b)

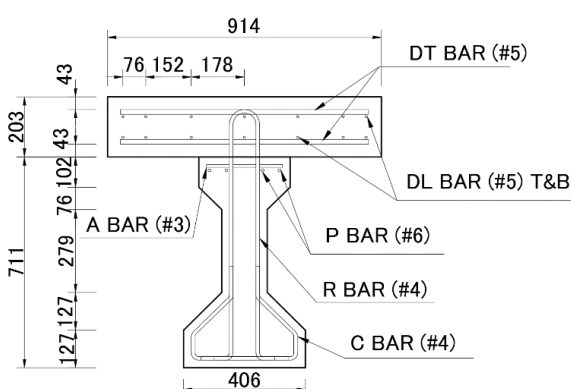

(c)

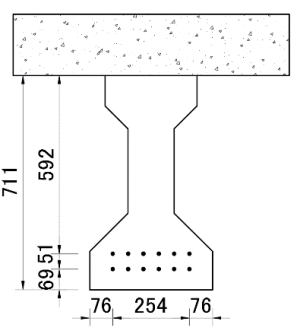

(d)

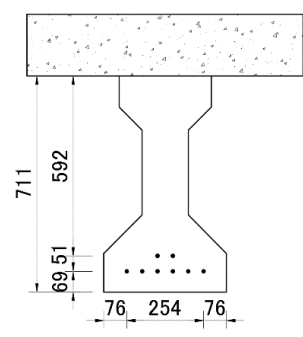

(e)

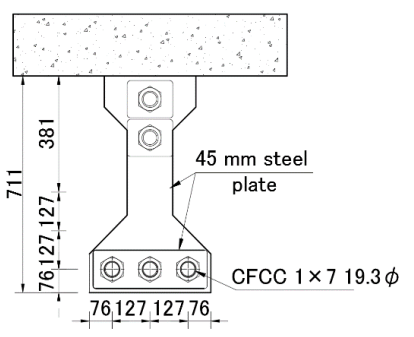

(f)

Fig. 2. Schematic drawings of the four prestressed beams: elevation and reinforcement details of a) post-tensioned beam with straight and draped cables b) pre-tensioned beams, c) typical reinforcement distribution, and typical dimensions for prestressed beams d) CPrSM, e) BPrSM, and f) CPouDF and CPoDM.

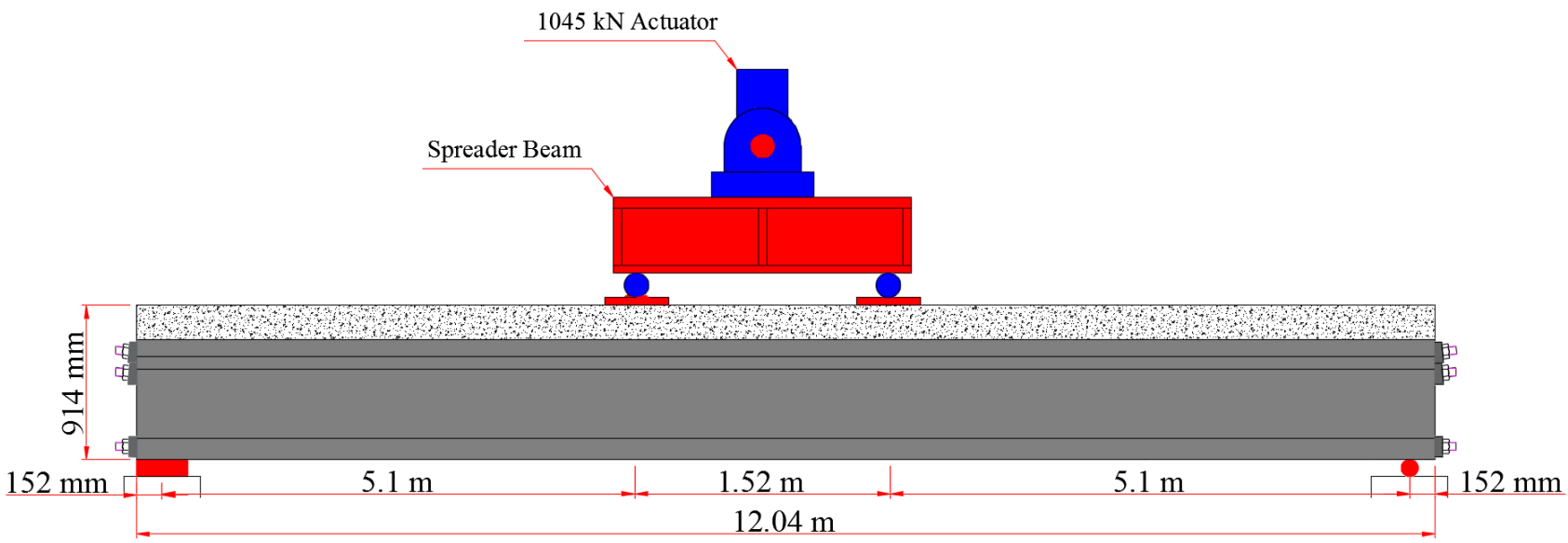

Fig. 4. Test setup for flexural testing 


\subsection{Test Set-up}

The beams were tested under four-point monotonic flexural loading. The applied load was measured with a calibrated load cell attached to the hydraulic actuator with $1045 \mathrm{kN}$ capacity as shown in Figure 4. Twelve string potentiometers along the length of the beam were used to measure the deflections of the beams.

\subsection{Testing protocols}

The testing of the beams in monotonic flexural loading was performed in displacement control mode. Prior to cracking, the beams were loaded with a rate of 0.84 $\mathrm{mm} / \mathrm{min}$. After cracking, the loading rate was increased to $4.24 \mathrm{~mm} / \mathrm{min}$. up to $75 \%$ of the estimated capacity and $3.05 \mathrm{~mm} / \mathrm{min}$. afterwards until failure. A $66.7 \mathrm{kN}$ seating load was applied at the beginning to reduce the initial slack of the load path.

\subsection{Results}

\subsubsection{Load-deflection curves}

Figure 5 shows the load-deflection curves of the four CFRP prestressed beams. The displacements presented in the figure are the average of two potentiometers at midspan, and the applied load is measured from the load cell on the actuator. The presented load does not include the weight of the beam and the composite deck.

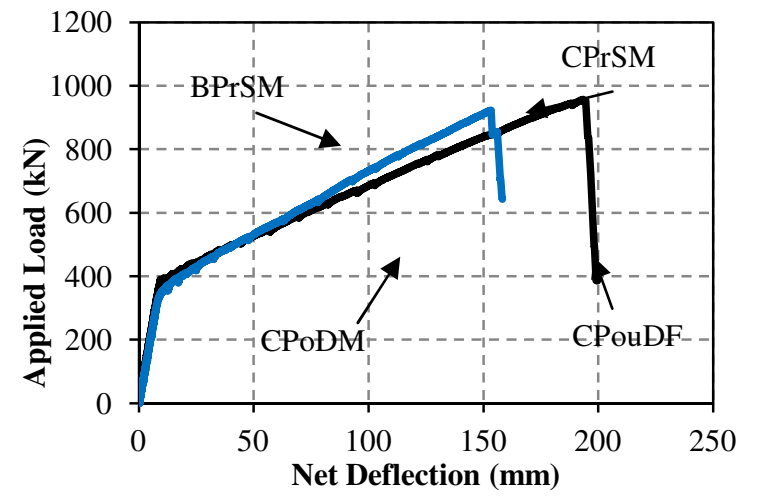

Fig. 5. Experimental load-deflection response of CFRP prestressed beams

Table 2. Summary of the test results

\begin{tabular}{|c|c|c|c|c|}
\hline $\begin{array}{l}\text { Beam } \\
\text { ID }\end{array}$ & $\begin{array}{c}\text { Cracking } \\
\text { Load } \\
(\mathrm{kN})\end{array}$ & $\begin{array}{c}\text { Ultimate } \\
\text { Load } \\
(\mathrm{kN})\end{array}$ & $\begin{array}{l}\text { Deflection } \\
\quad(\mathrm{mm})\end{array}$ & $\begin{array}{l}\text { Failure } \\
\text { Mode }\end{array}$ \\
\hline CPrSM & 320 & 936 & 196 & \multirow{3}{*}{$\begin{array}{l}\text { Cable } \\
\text { rupture }\end{array}$} \\
\hline $\mathrm{BPrSM}$ & 338 & 920 & 152 & \\
\hline CPoDM & 362 & 778 & 132 & \\
\hline CPouDF & 320 & 636 & 226 & $\begin{array}{l}\text { Concrete } \\
\text { crushing }\end{array}$ \\
\hline
\end{tabular}

The overall behavior of the beams were piece-wise linear with two distinct stiffnesses up to failure. The initial stiffnesses of the beams reduced after the crack openings and remained almost constant up to ultimate load. For the pre-tensioned beams and bonded posttensioned beam, the failure was due to rupture of the cables, and the load carrying capacity dropped to zero immediately. However, for the unbonded post-tensioned beams, the failure was due to concrete crushing and once the beams reached the ultimate load, there was a drop, but the beams had a reserved load carrying capacity. A summary of the test results is presented in Table 2 .

\subsubsection{Failure Modes and crack distributions}

The monotonic tests of the full-scale beams were done in stages to, 1) draw the crack propagation and 2) measure the crack width. The cracks of the unbonded posttensioned beams were concentrated in few wide cracks which forked with the loading during the test. This behavior is the same as unbonded post-tensioned with prestressing steel. However, for bonded prestressed beams, the cracks were spread over more than a quarter of the length from the center of the beam on each side. Figure 6 shows the failure modes and crack distribution at the peak load for the prestressed beams with CFRP systems.

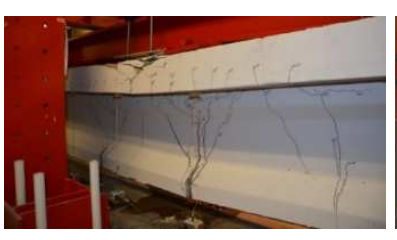

(a)

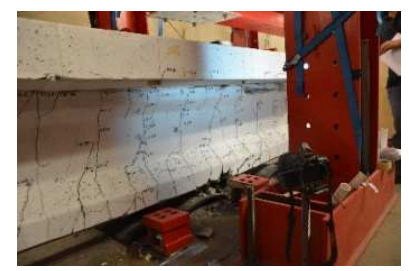

(c)

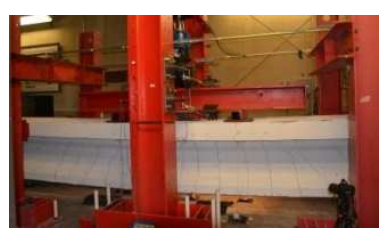

(b)

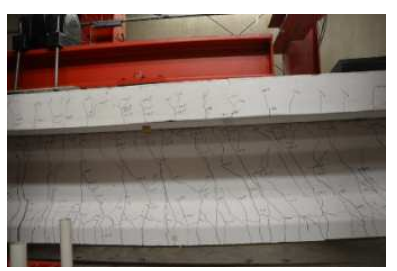

(d)
Fig. 6. Crack distribution and failure mode at the ultimate load for; a) CPouSM, b) CPoDM, c) CPrSM, and d) BPrSM.

\subsubsection{Crack width}

The crack widths were manually measured in addition to continuously recording by using non-contact instruments during the monotonic tests. The maximum crack opening against the applied load near the mid-span is shown in Figure 7, for all tested beams. As shown in the figure, the unbonded beams have a higher cracking width than the bonded case (up to seven times the crack width of bonded beams). 


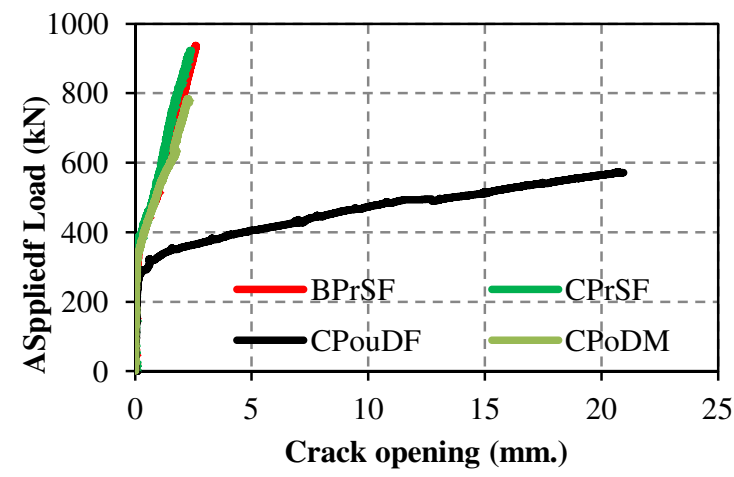

Fig. 7. Maximum crack opening measurements for the beam prestressed

\subsubsection{Deflection profile}

The deflection profile is obtained from the string potentiometers located along the beam length. In the locations where having potentiometers on both sides, the average displacement between the two potentiometers was taken while calculating the deflections. Figure 8 shows a comparison between the deflections of the tested beams at the ultimate load.

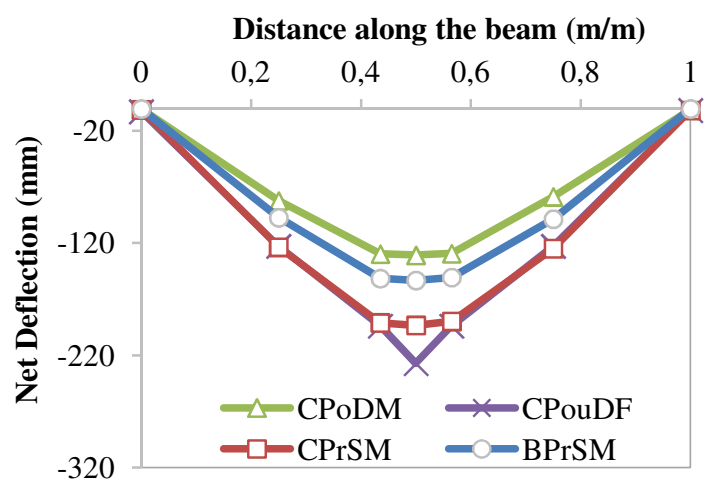

Fig. 8. Comparison of deflection profiles for the full-scale prestressed beam at the ultimate

\subsubsection{Cable load}

During the experimental tests, the cable force was recorded through a load cell attached to the dead end of some of the unbonded cables while the strain of the bonded cables was measured through a pre-attached strain gauge.

Figure 9 shows the change in the force of the middle bottom cable in the post-tensioned beams for two cases; unbonded in the beam CPouDF and bonded in the beam CPoDM. The results are plotted against the applied load.

At a same applied load level, the bonded case has less increase in cable force compared to the unbonded cables, however, at the same net deflection the increase in cable load is higher for the bonded case.

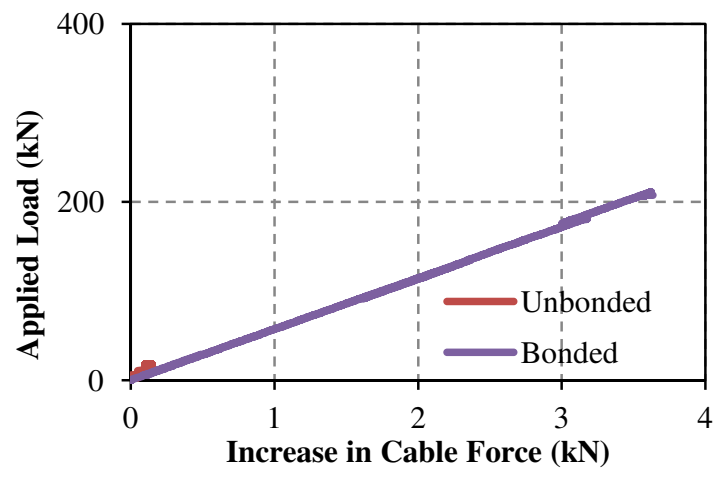

Fig. 9. Increase in cable force for the middle bottom cable for post-tensioned beams against the applied load for the bonded and unbonded case.

\section{SUMMARY AND CONCLUSION}

The preliminary results from the experimental tests showed that the CFRP prestressed beams demonstrate enough warning prior to failure. In addition, the deformability of the post-tensioned beams with unbonded prestressing CFRP cables are higher than the other CFRP pretensioned beams. However, the ultimate strength was lower than all the other bonded beams.

\section{ACKNOWLEDGEMENTS}

This research Project was funded by National Cooperative Highway Research Program (NCHRP). The views expressed in this paper are mostly of the authors and do not necessarily reflect the views of the funding agency.

\section{REFERENCES}

1. J. Warwaruk, M.A.Sozen, C.P. University of Illinois at Urbana-Champaign,(1960)

2. H.C. Ozyildirim, S.R. Sharp, Virginia Concrete Conference, March, (2013)

3. W. Podolny Jr, PCI Journal, 37(5), 34-55 (1992)

4. M. Nagi, D. Whiting, Special Publication, 151, (1994)

5. J.J. Myers, T. Viswanath, Structures Congress 2006: Structural Engineering and Public Safety, 1-8 (2006)

6. A.A. Abdelrahman, G.Tadros, S.H. Rizkalla, ACI Structural Journal, 92, 4 (1995)

7. C. W. Dolan, H. R. Hamilton, C. E. Bakis, and A. Nanni, Report DTFH61-96-C-00019, May(2000)

8. S. Heo, S. Shin, C. Lee, Journal of Composites for Construction, 17, 2 (2012)

9. A. Braimah, M.F. Green, T.I. Campbell, Canadian Journal of Civil Engineering,33, (2006)

10. T.Kakizawa, S.Ohno, T. Yonezawa, Special Publication, 138,(1993)

11. N.F. Grace, B.M. Tang, and G.A. Sayed, International Conference on FRP Composites in Civil Engineering, (2001) 